\title{
PESQUISA-AÇÃO SOBRE SEXUALIDADE HUMANA: UMA ABORDAGEM FREIRIANA EM ENFERMAGEM
}

\author{
Iara Sescon Nogueira ${ }^{1}$, Célia Maria Gomes Labegalini ${ }^{2}$, Karen Fernanda Ramos Pereira ${ }^{3}$, Ieda Harumi \\ Higarashi $^{4}$, Sonia Maria Villela Bueno ${ }^{5}$, Vanessa Denardi Antoniassi Baldissera ${ }^{6}$
}

\begin{abstract}
RESUMO: Objetivou-se descrever o percurso de uma ação educativa contextualizada, participativa e dialógica na temática sexualidade. Trata-se de estudo qualitativo do tipo pesquisa-ação crítica, delineado seguindo o referencial teórico-metodológico de Freire, tendo como público alvo 151 alunos matriculados no curso de graduação em enfermagem de uma universidade pública do Noroeste do Estado do Paraná, durante o mês de março de 2014. Destes, participaram 20 acadêmicos na fase de investigação temática e nove nos Círculos de Cultura. Seguiu todos os preceitos éticos. Pautado em situações-limites, desenvolveram-se Círculos de Cultura abordando os seguintes temas: "Conceito de Sexualidade", "Dimensão Psicológica e Social da Sexualidade" e "Assistência Integral em Sexualidade". Conclui-se que o desenvolvimento da ação educativa dialógica, pautada em situações-problemas reais, apresentou-se como um caminho viável para a reflexão da temática e para a construção de novos conhecimentos às práticas de cuidado que envolvem a sexualidade humana.

DESCRITORES: Educação em enfermagem; Enfermagem; Sexualidade; Estudantes de enfermagem.
\end{abstract}

\section{ACTION RESEARCH ABOUT HUMAN SEXUALITY: A FREIRIAN APPROACH IN NURSING}

ABSTRACT: The objective of this study was to describe the trajectory of a contextualized, participatory and dialogical educational action about sexuality. It was a qualitative study using critical action research, in accordance with the theoretical and methodological framework of Brazilian educator Paulo Freire. This investigation included 151 undergraduate nursing students in a public university in the northwest region of the state of Paraná, Brazil, and occurred in March 2014. Of this population, twenty students participated in the thematic investigation phase and nine in the culture circles. All ethical precepts were followed. Based on limit situations, the culture circles addressed the following themes: "The Concept of Sexuality", "Psychological and Social Dimensions of Sexuality", and "Comprehensive Care in Sexuality". The development of dialogical educational action, based on real-life problem situations was presented as a viable path for reflecting on the theme and building new knowledge for care practices involving human sexuality. DESCRIPTORS: Nursing Education; Nursing; Sexuality; Nursing Students.

\section{INVESTIGACIÓN-ACCIÓN SOBRE SEXUALIDAD HUMANA: UN ABORDAJE FREIRIANO EN ENFERMERÍA}

RESUMEN: Se objetivó describir el itinerario de una acción educativa contextualizada, participativa y dialógica en la temática sexualidad. Estudio cualitativo, tipo investigación-acción crítica, delineado siguiendo el referencial teórico-metodológico de Freire, con un público objetivo de 151 alumnos matriculados en curso de grado en enfermería de universidad pública del Noroeste del Estado de Paraná, durante marzo de 2014. De ellos, participaron 20 estudiantes en la fase de investigación temática, y nueve en los Círculos de Cultura. Se respetaron todos los preceptos éticos. Pautado en situaciones límite, se desarrollaron Círculos de Cultura, abordando los temas: "Concepto de Sexualidad"; "Dimensión Psicológica y Social de la Sexualidad"; y "Atención Integral en Sexualidad". Se concluyó en que el desarrollo de la acción educativa dialógica, pautada en situaciones-problemas reales, se mostró como un camino viable para la reflexión de la temática y para construir nuevos conocimientos a las prácticas de cuidado que involucran la sexualidad humana.

DESCRIPTORES: Educación en Enfermería; Enfermería; Sexualidad; Estudiantes de Enfermería.

${ }^{1}$ Enfermeira. Mestranda em Enfermagem. Universidade Estadual de Maringá. Maringá, PR, Brasil.

${ }^{2}$ Enfermeira. Mestre em Enfermagem. Universidade Estadual de Maringá. Maringá, PR, Brasil.

${ }^{3}$ Enfermeira. Missão Antioquia. Araçariguama, SP, Brasil.

${ }^{4}$ Enfermeira. Doutora em Educação. Docente de Enfermagem da Universidade Estadual de Maringá. Maringá, PR, Brasil.

${ }^{5}$ Pedagoga. Doutora em Educação. Docente da Escola de Enfermagem de Ribeirão Preto da Universidade de São Paulo. Ribeirão Preto, SP, Brasil.

${ }^{6}$ Enfermeira. Doutora em Ciências. Docente de Enfermagem da Universidade Estadual de Maringá. Maringá, PR, Brasil.

Autor Correspondente:

Recebido: 09/04/2016

lara Sescon Nogueira

Finalizado: 05/12/2016

Universidade Estadual de Maringá

R. Hélio Jarreta 54 - 87005-030 - Maringá, PR, Brasil

E-mail: iara_nogueira@hotmail.com 


\section{- INTRODUÇÃO}

A educação profissional busca qualificar os educandos para a consciência dos seus deveres sociais e conduzir à formação de profissionais capacitados ${ }^{(1)}$. No tocante ao profissional da saúde almeja-se que a educação seja capaz de fazê-lo compreender o homem no seu meio e os influentes no processo saúde-doença $^{(2)}$. A formação do enfermeiro brasileiro, entretanto,encontra dificuldades para esse intento, pois se mantém historicamente baseada no modelo biomédico, com destaque à assistência de enfermagem centrada em procedimentos técnicos, sem valorizar a multidimensionalidade humana ${ }^{(3)}$.

Nesse contexto, os movimentos educacionais atuais buscam ressignificar a práxis do cuidado e nessa perspectiva a sexualidade tem sido inserida nos currículos de enfermagem, em especial no âmbito da saúde da mulher e na educação sexual de adolescentes ${ }^{(1-4)}$, possibilitando ampliar as dimensões de cuidado e de promoção da saúde. Consequentemente, a formação nessa temática pode contribuir para impactar positivamente nas fragilidades de atuação profissional ${ }^{(4-5)}$.

Infelizmente tem se observado que o assunto sexualidade é tratado a partir do caráter de eventualidade e informalidade, ou ainda abordado sob enfoque de neutralidade, proibições e assexualização humana ${ }^{(4-6)}$. Isso tem tornado frágil a formação de enfermeiros nesse contexto ${ }^{(2,6)}$, pois carecem estar livres de mitos, crendices e tabus para que de fato contribuam com adequado manejo social da temática ${ }^{(6)}$.

Tal demanda de formação implica em um processo de aprendizagem que contrarie os preceitos do ensino tradicional em que a transmissão de conhecimentos do educador para o educando é privilegiada, mas que se distanciada realidade vivenciada pelo aluno ${ }^{(7-8)}$ e o impede da criticidade necessária para a transformação de seus conhecimentos e de suas práticas.

Para romper com esse modelo de ensino tradicional, Paulo Freire, na década de 1970, desenvolveu a perspectiva da educação dialógica e emancipatória, que tem no diálogo autêntico a base para o desenvolvimento do pensamento crítico em torno de um fato concreto, capaz de remodelar saberes e fazeres. Assim, Freire afirmou que a leitura do mundo não é somente da palavra que torna homens e mulheres pensantes e engajados na reconstrução da sua realidade, mas por meio de ação que se faz mediada pela educação no contexto da ação-reflexão-ação ${ }^{(7)}$.

A abordagem freireana privilegia o diálogo no processo de aprendizagem por conceber que o conhecimento somente é construído na interação entre os homens balizados por sua realidade $\operatorname{concreta}^{(7)}$. Ancorados nesse referencial teórico e metodológico buscou-se, por meio dessa pesquisa, a concretização de uma proposta educativa, pautada no diálogo, que culminasse na construção coletiva do conhecimento e na reflexão das práticas pelos próprios educandos ${ }^{(7)}$.

Assim, a questão da presente pesquisa, definida a priori, foi: como seria a construção de uma ação educativa dialógica e emancipatória em sexualidade com graduandos em enfermagem? Para responder a esse questionamento, objetivou-se descrever o percurso de uma ação educativa contextualizada, participativa e dialógica na temática sexualidade desenvolvida com graduandos de enfermagem.

\section{- MÉTODO}

Tratou-se de um estudo qualitativo com abordagem da pesquisa-ação crítica destinado a buscar a realidade concreta da temática sexualidade, suas explicações e superação do conhecimento ingênuo por meio do desenvolvimento de ação educativa pelos pesquisadores e participantes do estudo ${ }^{(7)}$, denominados atores da pesquisa.

Com a finalidade de transformação dos saberes e práticas( ${ }^{(7)}$ no entorno da sexualidade, a temática proposta foi de iniciativa dos pesquisadores, mas o levantamento da realidade vivida e a ação educativa desenvolvidas foram pactuadas pelos atores, acontecendo de forma participativa e contextualizada, permitindo que o percurso da investigação e ação fossem dialógicas e participativas ${ }^{(9)}$.

O estudo teve como público-alvo os 151 acadêmicos matriculados no curso de graduação em enfermagem de uma universidade pública do Noroeste do Estado do Paraná, que aceitaram participar 
da mesma, independente da série que cursavam, tal qual exigem os referenciais da pesquisa-ação crítica $^{(7)}$.

Todos os acadêmicos do curso de graduação em enfermagem foram convidados a participar do estudo, por meio de abordagem oral realizada durante o intervalo das aulas. Os critérios de inclusão para participação na pesquisa foram: estar devidamente matriculado no curso de enfermagem dessa instituição e consentir em participar do estudo. Destes, participaram 20 respondentes do questionário (investigação temática), selecionados por amostra intencional uma vez que manifestaram interesse na temática e, posteriormente, permaneceram nove nos Círculos de Cultura, pois foram aqueles que se sentiram confortáveis para discutir a sexualidade em grupo.

Para seu desenvolvimento adotou-se o referencial teórico-metodológico de Freire ${ }^{(7)}$, cujo itinerário de pesquisa foi composto de três fases interdependentes: Investigação Temática; Codificação/ Descodificação e Desvelamento Crítico.

A investigação temática desenvolveu-se utilizando um questionário aberto elaborado pelas pesquisadoras com questões referentes à caracterização dos participantes e suas concepções sobre a sexualidade humana. Nessa fase buscou-se levantara temática proposta, na perspectiva de seus participantes, para que os diálogos acontecessem na direção de sua realidade.

Para a validação dessa investigação temática, uma análise prévia dos questionários permitiu que os pesquisadores apreendessem a representação da temática pelos participantes. Essa análise culminou na definição de situações-limites conceituadas como situações-problemas reais ${ }^{(7)}$ que poderiam ser superadas pela reflexão daqueles que dela fazem parte.

Assim, os pesquisadores elencaram as situações-limites e as apresentaram aos participantes, para que, em Círculos de Cultura (CC), pudessem reconhecê-las ou refutá-las como reais. A ação educativa, portanto, desenvolveu-se em CC, compreendido como espaços dinâmicos de aprendizagem e troca de conhecimentos. Assim sendo, os sujeitos reúnem-se no processo de educação para desvelar criticamente o que é de interesse do próprio grupo ${ }^{(7)}$.

Os CC foram realizados em dois dias sequenciais, durante o mês de março de 2014, totalizando seis horas, para que pudesse ocorrer a validação da investigação temática previamente levantada na fase anterior e concretizar a codificação/descodificação e o desvelamento crítico que compõem o itinerário de pesquisa adotado.

Cumpre destacar que nos CC não estiveram presentes todos os participantes da fase de investigação temática, visto que ocorreram em momentos distintos e alguns declinaram sua participação. Essa situação não desabonou o estudo, tão pouco lhe causou prejuízos. Intencionado ao cumprimento dos princípios éticos e rigor metodológico, o estudo seguiu-se com o quantitativo que manifestou interesse.

Validadas em CC como realidade concreta,das situações-limites elegeram-se temas geradores para serem, então, codificados. A codificação caracterizou-se como momento em que foi concedida ao aluno a oportunidade de falar sobre os temas geradores eleitos, ocorrendo à descoberta do que pensavam sobre a sexualidade e os limites desse saber. Nesta fase, os alunos foram questionados para melhor compreender o que pensava e/ou sabia a respeito dos temas geradores.

Esses temas codificados foram descodificados e reconhecidos por meio de um processo crítico e reflexivo, emergindo uma situação presente, real e prática, da qual insurgiram as aspirações dos participantes sobre sua superação ${ }^{(10)}$.

A descodificação foi, portanto, o momento em que foi introduzida a discussão com vistas à inter-relação entre senso comum e científico, permitindo que o participante fizesse uma releitura e, consequentemente a transformação de sua visão de mundo. Nesta fase, buscou-se direcionar as discussões com questionamentos que estimulassem a reflexão sobre o tema em forma de debate.

Nesse processo desenvolveram-se diálogos autênticos - por serem críticos e reflexivos - entre os atores da pesquisa, propiciando o que se denomina de desvelamento crítico,ocorrido no movimento de ir e vir dos conceitos prévios aos novos conceitos que foram desvelados, concretizando o movimento de ação-reflexão-ação, sugestivo de mudanças da realidade ${ }^{(7,10)}$. 
O presente trabalho está vinculado à pesquisa institucional docente 'Pesquisa-ação nas demandas educativas no cenário da enfermagem' (Protocolo 401/2013) cujo parecer do Comitê Permanente de Pesquisa com Seres Humanos da Universidade Estadual de Maringá foi favorável (28/08/2013) à sua realização, sob o n.375.459/2013, e seguiu todos os preceitos éticos da Resolução 466/2012 do Conselho Nacional de Saúde ${ }^{(11)}$. Assim, foi desenvolvido junto ao Grupo de Estudos e Pesquisas em Práticas Educativas em Saúde (GEPPES), cadastrado no Diretório de Pesquisas do Conselho Nacional de Desenvolvimento Científico e Tecnológico (CNPq).

\section{RESUlTADOS}

\section{Caracterização dos sujeitos e percurso da ação educativa}

Na fase de investigação temática inicial participaram 20 graduandos com idades que variavam de 18 a 24 anos, com média de 20,2 anos. Dentre estes, 19eram do sexo feminino (95\%) e um masculino $(5 \%) ; 19$ solteiros (95\%) e um casado (5\%). Entre os acadêmicos, quatro cursavam o primeiro ano da graduação $(20 \%)$, quatro o segundo (20\%), cinco alunos o terceiro ano $(25 \%)$ e sete o quarto ano (35\%).

Sobre moradia, 15 alunos residiam com os pais ou familiares (75\%), três em república (15\%) e dois moravam sozinhos (10\%). Todos os alunos (100\%) relataram que não trabalhavam, sendo assim, dependentes financeiramente. Em relação à questão econômica, oito participantes $(40 \%)$ se abstiveram da resposta, os respondentes $(n=12 / 60 \%)$ relataram que os rendimentos variavam de 1 a 16 salários mínimos. A religião predominante entre os acadêmicos foi à católica ( $\mathrm{N}=11 / 55 \%)$, seguido de evangélica $(\mathrm{N}=8 / 40 \%)$ e um $(5 \%)$ relatou não ser adepto a nenhuma religião.

$\mathrm{Na}$ fase de desenvolvimento da atividade educativa, participaram nove acadêmicos, sendo oito no primeiro dia e sete no segundo. O total de nove participantes deu-se pela presença de diferentes participantes durante os dois dias. Participaram oito (89\%) estudantes do sexo feminino e um (11\%) do sexo masculino.

Retomando ao percurso metodológico, cumpre esclarecer que no itinerário de Freire as situaçõeslimites fazem parte da investigação temática e previamente foram definidas pelos pesquisadores a partir da análise preliminar das falas dos participantes registradas nos questionários aplicados (Quadro 1).

Quadro 1 - Situações-limites e falas que as descrevem. Maringá, PR, Brasil, 2014

\begin{tabular}{|c|c|}
\hline Situações-limites & alas que as descrevem \\
\hline \multirow{2}{*}{$\begin{array}{l}\text { A sexualidade é } \\
\text { percebida em suas } \\
\text { múltiplas facetas } \\
\text { com reducionismo à } \\
\text { genitalidade. }\end{array}$} & $\begin{array}{l}\text { Sexualidade para mim é o ato de sentir prazer por outra pessoa e ter relações sexuais com } \\
\text { ela ou masturbação. (P2) }\end{array}$ \\
\hline & Sexualidade é um conjunto de sentimentos que resultam em um ato. (P3) \\
\hline \multirow{3}{*}{$\begin{array}{l}\text { A formação dos } \\
\text { acadêmicos de } \\
\text { enfermagem sobre a } \\
\text { sexualidade humana } \\
\text { é frágil durante a } \\
\text { graduação. }\end{array}$} & $\begin{array}{l}\text { Ainda não recebi muito preparo sobre essa temática na graduação. Só aprendi sobre os } \\
\text { contraceptivos e algumas abordagens. (P1) }\end{array}$ \\
\hline & No curso, em minha opinião, tivemos pouco preparo nesta questão. (P10) \\
\hline & $\begin{array}{l}\text { O preparo teórico sobre o tema foi superficial, e o que construímos foi durante a prática em } \\
\text { estágio. (P18) }\end{array}$ \\
\hline \multirow{3}{*}{$\begin{array}{l}\text { As práticas de } \\
\text { enfermagem acerca da } \\
\text { sexualidade humana se } \\
\text { concretizam através de } \\
\text { orientações. }\end{array}$} & $\begin{array}{l}\text { [...] orientando as pessoas dos riscos sobre o sexo sem prevenção e a forma de preveni-los. } \\
\text { Pretendo fazer sempre que puder e principalmente quando a pessoa demonstra indícios de } \\
\text { praticar sexo.(P2) }\end{array}$ \\
\hline & $\begin{array}{l}\text { [...] quando encontro adolescentes ou até adultos pergunto se possuem alguma dúvida, se } \\
\text { já pratica relação sexual, e procuro orientar sobre os métodos contraceptivos e solucionar } \\
\text { as dúvidas apresentadas. (P10) }\end{array}$ \\
\hline & $\begin{array}{l}{[. . .] \text { se estas pessoas recebem orientações acerca da realidade em que vivem e se prevenirem }} \\
\text { dos riscos, não vai causar impactos ou agravos na sua saúde física. (P15) }\end{array}$ \\
\hline
\end{tabular}


Embasados nas situações-limites (Quadro 1), procedeu-se à elaboração da ação educativa que foi delineada por meio de CC para permitir o diálogo emancipador a partir da codificação/decodificação e desvelamento crítico. Nesse sentido, a ação educativa foi denominada de "Sexualidade: dialogando olho no olho", remetendo à ideia de educação contextualizada, participativa e dialógica. O percurso dos Círculos de Cultura que caracterizaram essa ação educativa serão apresentados a seguir, na ordem de sua realização, a partir das situações-limites disparadoras.

O primeiro CC iniciou-se com a apresentação de todos os integrantes do grupo e um breve relato de suas expectativas ao participar dessas atividades. As respostas centraram-se acerca do aumento do conhecimento sobre o assunto, dúvidas sobre a temática e de reconhecimento quanto à importância do conteúdo em suas vidas profissionais.

Em seguida elaborou-se um contrato de convivência durante as atividades, escrito em folha de cartolina e deixada em local visível nos dois dias de CC, no qual "guardar dúvidas" e "sigilo" foram evidenciados como situações que não gostariam, como também gostariam que ocorresse, respectivamente.

Em seguida, realizou-se uma dinâmica para conhecer os saberes dos participantes sobre o tema sexualidade, permitindo a validação da investigação temática realizada por meio dos questionários.

A dinâmica deu-se da seguinte forma: cada aluno recebeu três papéis de cores e significados diferentes (verde: resposta afirmativa, vermelho: resposta negativa e amarela: sem resposta/não sabe) de maneira que pudessem sinalizar o que sabiam sobre cada afirmativa apresentada pela pesquisadora. Estas foram elaboradas baseadas nas situações-limites encontradas na investigação temática, a saber: A sexualidade se resume em ato sexual; A sexualidade inicia-se na puberdade; A enfermagem tem como papel na sexualidade, intervir na vida de alguém quanto à prevenção de infecções sexualmente transmissíveis (IST's) e métodos contraceptivos; É importante falar em sexualidade voltada para enfermagem; A sexualidade define o papel do homem e da mulher na sociedade; dentre outras. Por meio destas afirmativas, possibilitou um contato maior com uma dimensão ampliada da sexualidade.

Os participantes demonstraram um conceito mais ampliado de sexualidade do que previamente identificado nos questionários, pois evidenciaram outros saberes e valorização das dimensões psicológica e social da sexualidade; contudo, a dimensão biológica era mais evidente. Isso levou os atores da pesquisa a confirmarem a situação-limite e desencadearem as demais fases do itinerário de pesquisa, conforme demonstra Figura 1.

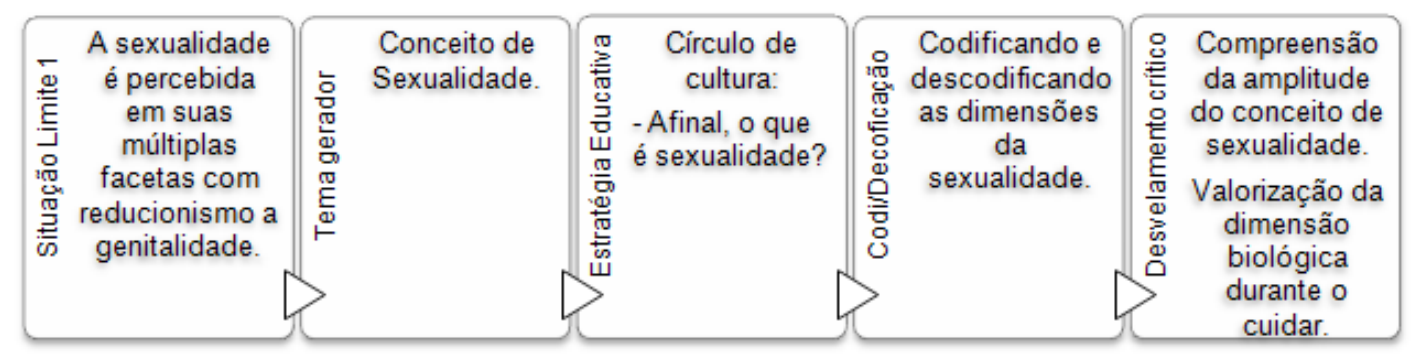

Figura 1 - Situação limite 1, tema gerador, estratégia educativa, codificação/decodificação e desvelamento crítico. Maringá, PR, Brasil, 2014

A construção de um novo conceito de sexualidade foi o desvelamento esperado e, para isso, elegeu-se o tema gerador 'conceito de sexualidade' cuja estratégia educativa foi uma dinâmica a ser realizada em CC, permitindo a codificação e descodificação. Os participantes, em meia folha de sulfite escreveram uma palavra que, na opinião deles, relacionava-se com a sexualidade. Após isto, as palavras foram coladas no quadro, correlacionando-as com seus respectivos aspectos: biológico, psicológico e social, os quais refletem as diversas dimensões da sexualidade humana.

Em seguida, o grupo foi dividido primeiramente em duplas a fim de construir o novo e amplo conceito de sexualidade humana, abrangendo todas as dimensões da mesma. Os novos conceitos foram dialogados pelos atores e desvelados criticamente, anunciando profundas transformações na 
forma de pensar a temática e sua incorporação nas práticas de enfermagem.

Na dimensão biológica da sexualidade foram dialogados os temas correlacionados, como anatomia, fisiologia e genética. As transformações hormonais e genitais que acompanham a adolescência e a senilidade foram amplamente discutidas, trazendo vivências pessoais e profissionais. As reflexões sobre o aspecto biológico da sexualidade permitiram considerá-lo relevante para o desenvolvimento saudável do indivíduo, mas também desvelaram a relação com mitos, crendices e tabus, já apontando para a relação com as outras dimensões da sexualidade, ressaltando a importância da enfermagem na sua abordagem, bem como o desenvolvimento da atual prática desse profissional que normalmente centra-se nos aspectos biológicos para a distinção entre o normal e o patológico.

O segundo CC procurou dialogar a formação acadêmica, trazendo a situação-limite previamente estabelecida para ser validada. Considerando as reflexões já apontadas no CC anterior, os atores consideraram que as dimensões psicológicas e sociais são as mais frágeis e que sinalizavam necessidade de superação. Por essa razão, foram eleitos como temas geradores e deveriam ser foco do diálogo emancipador, tal qual foi conduzido, ilustrado no esquema a seguir:

\begin{tabular}{|c|c|c|c|c|c|c|c|c|c|}
\hline 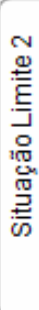 & $\begin{array}{c}\text { A Formação } \\
\text { dos } \\
\text { acadêmicos de } \\
\text { enfermagem } \\
\text { sobre a } \\
\text { Sexualidade } \\
\text { Humana é } \\
\text { frágil durante a } \\
\text { graduação. }\end{array}$ & 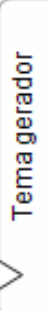 & $\begin{array}{c}\text { Dimensão } \\
\text { psicológica e } \\
\text { social da } \\
\text { sexualidade. }\end{array}$ & 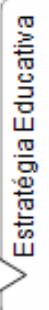 & $\begin{array}{l}\text { Círculo de } \\
\text { cultura: } \\
\text { - Dimensão } \\
\text { psicológica da } \\
\text { sexualidade. } \\
\text { - Dimensão } \\
\text { social da } \\
\text { sexualidade. }\end{array}$ & 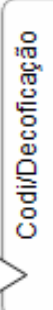 & $\begin{array}{l}\text { Compreensão } \\
\text { psicológica da } \\
\text { sexualidade. } \\
\text { Compreensão } \\
\text { cultural da } \\
\text { sexualidade. }\end{array}$ & 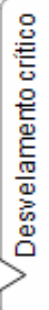 & $\begin{array}{l}\text { Necessidade } \\
\text { de refletir sua } \\
\text { sexualidade na } \\
\text { dimensão } \\
\text { psiquica. } \\
\text { Compreensão } \\
\text { determinação } \\
\text { social da } \\
\text { sexualidade. }\end{array}$ \\
\hline
\end{tabular}

Figura 2 - Situação limite 2, tema gerador, estratégia educativa, codificação/decodificação e desvelamento crítico. Maringá, PR, Brasil, 2014

Para desencadear reflexões e diálogos, esse CC iniciou-se com a dinâmica sobre a dimensão psicológica, intitulada: "Relaxamento e fortalecimento da autoestima" (Figura 2). Esta dinâmica trabalhou o "eu", conduzindo as pessoas a sentirem o seu corpo e suas particularidades. Para isso, o ambiente foi preparado, diminuindo a intensidade da luz e colocando uma música relaxante. Todos os participantes foram orientados a permanecer sentados de forma confortável e foram estimulados pela pesquisadora a relaxar seu corpo e sua mente. Essa atividade também auxiliou os participantes a vivenciarem a dimensão abordada, reconhecendo a sua própria sexualidade e seus sentimentos.

Logo após, realizou-se a dinâmica com os participantes em círculo, passando a cada um deles uma caixa com os dizeres: "Quem você vê?" e um espelho, de modo que os mesmos fizessem uma reflexão sobre eles mesmos e seu processo de autoconhecimento.

Ao fim das duas dinâmicas os participantes descreveram seus sentimentos e a maioria relatou que nunca havia realizado atividades voltadas para suas particularidades e a importância de sua individualidade. Dialogou-se o quanto essa vivência é importante para reconhecer-se a si mesmo e para reconhecer o outro no cuidado de enfermagem que envolve a sexualidade e exige o respeito à intimidade e à individualidade.

Após esse momento, seguiu-se para as dinâmicas relacionadas à dimensão social, objetivando a reflexão e desvelamento compartilhado. Os participantes foram convidados a escolher um animal que possuísse características semelhantes as suas. As características individuais citadas foram classificadas em categorias: feminino ou masculino. A partir disso, foram foco do diálogo as questões de gênero, o papel social e as imposições sociais para o homem e para a mulher.

O último CC teve por finalidade o desvelamento crítico da situação-problema intitulada: “As práticas de enfermagem acerca da Sexualidade Humana se concretizam através de orientações". Essa situaçãolimite foi validada pelos atores e desenvolvida a partir da definição coletiva do tema gerador 'promoção à saúde e a abordagem integral do usuário', como demonstra a Figura 3. 


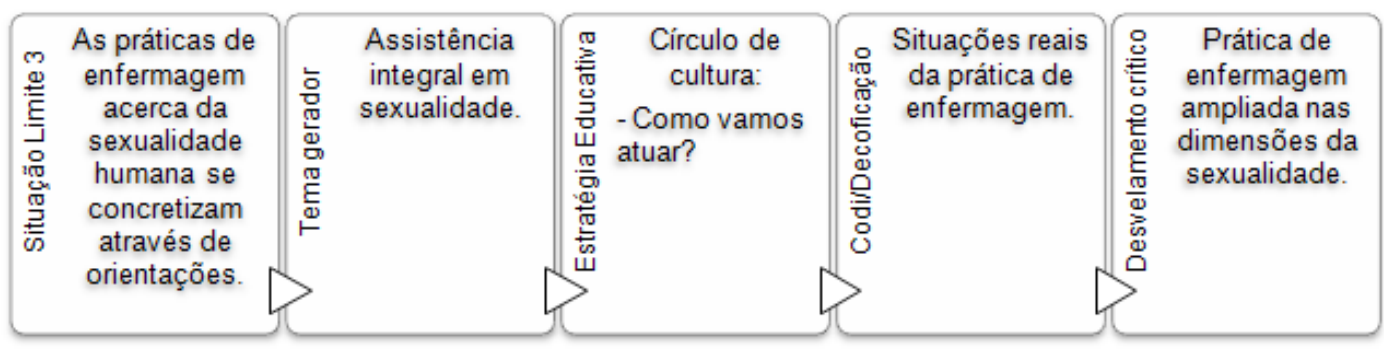

Figura 3 - Situação limite 3, tema gerador, estratégia educativa, codificação/decodificação e desvelamento crítico. Maringá,PR, 2014

Foi afirmado que os dilemas em relação à sexualidade humana são enfrentados por enfermeiros durante a prática profissional, mas também pelos alunos durante as atividades acadêmicas nas práticas clínicas e estágios.

Essa realidade concreta, apontada pelo grupo, foi codificada em vivências conflituosas e situações polêmicas vivenciadas pelos mesmos no entorno da sexualidade, dentre elas: deficiência física e/ou mental, menopausa, andropausa, educação sexual na escola, saúde do homem, exploração sexual, relações homoafetivas e violência sexual.

Assim, desvelou-se que as práticas de enfermagem devem abranger todas as dimensões da sexualidade humana.

Ao final dos CC, realizou-se avaliação do percurso educativo na perspectiva dos participantes. Relataram que a experiência foi proveitosa, pois os fizeram rever seu modo de pensar e conduzir as práticas profissionais que envolvem a sexualidade, mostrando novas possibilidades. Ademais, referiram aprovara abordagem utilizada, relatando que não conheciam e a avaliaram positivamente em função de "fugir do convencional" no que se refere às práticas educativas hegemonicamente realizadas no âmbito da academia.

\section{- DISCUSSÃO}

As situações-limites, entendidas como obstáculos que as pessoas podem encontrar nas suas vidas, frutos da ausência de criticidade do mundo que as cercam, podem colocar limites para suas condutas por dificuldades em superá-las ${ }^{(7)}$. Nesse sentido representa, para ações educativas emancipatórias, uma possibilidade desencadeadora do desvelamento crítico pelo fato de assumir sua existência. Daí a importância de serem reconhecidas nessa perspectiva de educação, pois nelas residem os temas geradores que cumprem o papel de ponto de partida para as reflexões e posterior superação ${ }^{(7)}$, tal qual o percurso dessa pesquisa desencadeou na temática da sexualidade.

No entanto, criar condições para o diálogo é condição irrevogável e só seria possível se planejado. Nessa perspectiva, um contrato entre os atores envolvidos, tal qual foi feito, justifica-se pela importância conferida ao que é pactuado constituindo-se em regras e limites definidos pelos envolvidos em uma ação participativa ${ }^{(7,10)}$. Tal definição permitiu a construção de um espaço de diálogo autêntico pela certeza de pertencimento ao grupo e responsabilidade pelo desenvolvimento de sua criticidade e também do outro. Pode-se considerar que a estratégia de contrato, adotada no início do primeiro CC, foi relevante para favorecer a participação dialógica.

A codificação da temática por meio de dinâmica foi importante para fortalecer o diálogo e possibilitou conhecer a realidade na qual cada participante estava inserido ${ }^{(2,10)}$. Os momentos de desvelamento crítico foram marcados pela tomada de consciência crítica da realidade gerando iniciativas ou propostas de ação ${ }^{(7)}$ no que se refere à dimensão da sexualidade no cuidado de enfermagem.

Apreendeu-se que a sexualidade não era plenamente compreendida pelos participantes como fator individual e constituinte da personalidade humana, que se integram de forma indissociável aos demais aspectos da vida e relaciona-se aos aspectos biopsicossociais e espirituais do indivíduo, não se restringindo às questões da corporeidade, ao ato sexual, nem tão somente às características sexuais ${ }^{(3)}$. 
Por isso, o percurso dialógico da pesquisa percorreu estratégias dialógicas distintas até que os atores pudessem desvelá-la como a forma de cada indivíduo se expressar, se posicionar, se relacionar, tanto na vida amorosa e sexual como social ${ }^{(3,12)}$.

Nesse sentido, puderam de fato dialogar sobre as dimensões biológicas, psicológica e social da sexualidade apropriando-se dessa nova perspectiva ampla até então pouco conhecida e valorizada. Essa emancipação de conceito permitiu que os participantes a valorizassem a integralidade constituinte do ser humano levando-os, como pessoa e futuros profissionais da saúde, a reconhecerem essas dimensões em si e a considerarem que aquele que é cuidado, em suas práticas profissionais, também as têm ${ }^{(3,13)}$.

Isso ficou evidente no CC destinado a essa reflexão permeada pelo diálogo, quando os atores desvelaram a necessidade de refletir sobre eles mesmos e suas particularidades, assumindo que a dimensão psicológica da sexualidade está relacionada com a subjetividade ${ }^{(3,14)}$ e, por isso, nem sempre observada pelo enfermeiro em sua assistência.

No CC em que se dialogou a dimensão social da sexualidade, os participantes discutiram e refletiram as questões de gênero que designa a construção social do sexomasculino e feminino. Desvelaram que esse aspecto recai sobre as relações de poder balizadas pelas culturas e que são construídas pelas sociedades $^{(6,15)}$. Este momento possibilitou a troca e a valorização dos conhecimentos, permitindo que fossem transformadores ativos do processo de aprendizagem ${ }^{(7)}$. Tal postura participativa coaduna a formação profissional engajada e melhor preparada para o cuidado de enfermagem qualificado na sexualidade humana, capaz de colaborar com o manejo social que se constrói coletivamente nessa temática e que seria capaz de impactar no preconceito, na homofobia e na violência sexual.

No decorrer das dinâmicas, em especial ao abordar a dimensão social da sexualidade, observou-se que a construção social ainda coloca a mulher em uma posição de fragilidade e de vulnerabilidade. Entretanto, consegue-se apreender que os homens também sofrem essa influência social. Outro aspecto observado refere à predominância de destaques às características femininas, o que provavelmente foi influenciado pela predominância no grupo.

É possível destacar a fragilidade de estudos e discussões sobre sexualidade em ambiente acadêmico e profissional do enfermeiro. Quando são encontrados, se restringem à perspectiva biológica e patológica ${ }^{(6)}$ e, nesse sentido, evidenciam lacunas para as quais novos achados precisam ser partilhados.

Propiciar debates e reflexões acerca do cuidado integral em saúde durante a graduação, abrangendo a sexualidade humana, possibilita o desenvolvimento do olhar crítico e da postura sensível em relação à temática, instrumentalizando o futuro profissional para a integralidade da atenção em saúde. Certamente o efeito desta reflexão não se restringirá ao momento, mas servirá como um instrumento da prática do cuidado ${ }^{(6,16)}$.

Pode-se afirmar que o conhecimento ingênuo, no sentido da superficialidade que o caracterizava, foi superado pelo conhecimento crítico $^{(7)}$, com profundas reflexões sobre as condutas profissionais do enfermeiro nesse contexto, tão necessárias na atualidade.

\section{CONCLUSÃO}

O estudo demonstrou que os graduandos de enfermagem compreendiam a sexualidade com reducionismo à genitalidade e que a formação dos mesmos durante a graduação em relação à temática é frágil. Dessa forma, as práticas de enfermagem acerca da sexualidade humana se concretizam por meio de orientações biologicistas, segundo apontado pelos participantes.

Conhecer essas percepções foi essencial para o planejamento e desenvolvimento da ação educativa contextualizada à realidade dos acadêmicos e pautada nas premissas da dialogicidade. Nesse sentido, o uso do itinerário de pesquisa de Freire permitiu a construção coletiva de saberes e a criticidade das práticas, por meio da codificação/decodificação e do desvelamento crítico. Esta abordagem foi reconhecida pelos participantes como inovadora, e favorável para a mudança de paradigmas e tabus, estimulando o processo de ensino e aprendizagem com potencialidades para a aplicabilidade já nas atividades da graduação. 
Conclui-se que o desenvolvimento da ação educativa dialógica, pautada em situações- problemas reais, apresentou um caminho viável para a reflexão da temática, construção de novos conhecimentos e práticas de cuidado que envolvem a sexualidade humana.

Como limitação da pesquisa, destaca-se a impossibilidade de executar todas as fases dialógicas com a totalidade de participantes, visto que o tema da sexualidade foi direcionado pelos pesquisadores ao ser levantado primeiramente por questionário e que o quantitativo participante dessa fase não foi totalmente contemplado nas fases seguintes.

\section{REFERÊNCIAS}

1. Ministério da Educação (BR). Educação Profissional e Tecnológica. Brasília: Editora do MEC; 2008.

2.da Silva GF, Chrizostimo MM, Rosas AMMTF. O significado da formação profissional para o graduando de enfermagem da UFF frente ao seu futuro profissional. Enferm. glob. [Internet] 2010;(18) [acesso em 17 set 2015]. Disponível:http://scielo.isciii.es/pdf/eg/n18/pt_docencia4.pdf.

3. Costa LHR, Coelho ECA. Nursing and sexuality: integrative review of papers published by the Latin-American Journal of Nursing and Brazilian Journal of Nursing. Rev. Latino-Am. Enfermagem. [Internet] 2011;19(3) [acesso em 20 de ago 2015]. Disponível: http://dx.doi.org/10.1590/S0104-11692011000300024.

4. Garcia ORZ, Lisboa LCS. Consulta de enfermagem em sexualidade: um instrumento para assistência de enfermagem à saúde da mulher, em nível de atenção primária. Texto Contexto Enferm. [Internet] 2012;21(3) [acesso em 25 ago 2015]. Disponível: http://dx.doi.org/10.1590/S0104-07072012000300028.

5. Ressel LB, Budó MLD, Junges CF, Sehnem GD, Hoffmann IC, Büttenbender E. O significado de sexualidade na formação de enfermeiros. Rev enferm UFPE on line. [Internet] 2010;4(2)[acesso em 17 set 2015]. Disponível: http://www.revista.ufpe.br/revistaenfermagem/index.php/revista/article/view/808/pdf_34.

6. Sehnem GD, Ressel LB, Junges CF,da Silva FM, Barreto CN. A sexualidade na formação acadêmica do enfermeiro. Esc. Anna Nery.[Internet] 2013;17(1) [acesso em 17 set 2015]. Disponível: http://dx.doi.org/10.1590/ S1414-81452013000100013.

7. Freire P. Pedagogia do Oprimido. 21a ed. Rio de Janeiro: Paz e Terra; 2011.

8. Branco ML. A educação progressiva como alternativa: as vozes dos educadores. Educ. Soc. [Internet] 2014;35(127) [acesso em 20 ago 2015]. Disponível:http://www.redalyc.org/articulo.oa?id=87331479008.

9. El Andaloussi K. Pesquisas-ações: ciências, desenvolvimento, democracia. (M. Thiollent, Trad.). São Carlos: EdUFSCar; 2004.

10. Monteiro EMLM, Vieira NFC. Educação em saúde a partir de círculos de cultura. Rev. bras. enferm. [Internet] 2010;63(3) [acesso em 22 ago 2015]. Disponível:http://dx.doi.org/10.1590/S0034-71672010000300008.

11. Ministério da Saúde (BR). Conselho Nacional de Saúde. Diretrizes e normas regulamentadoras de pesquisa envolvendo seres humanos. Resolução n. 466, de 12 de dezembro de 2012. Brasília; 2012.

12.Moura ERF, Veras SS, Dias AA, Aguiar LNR, Nogueira PSF, Costa CBJS. Panorama clínico, terapêutico e sexual de mulheres portadoras de Papiloma Vírus Humano e/ou Neoplasia Intraepitelial Cervical. Rev. Enf. Ref. [Internet] 2014;4(3) [acesso em 22 ago 2015].Disponível: http://dx.doi.org/10.12707/RIII13177.

13. Cushman LF, Delva M, Franks CL, Jimenez-Bautista A, Moon-Howard J, Glover J,et al. Cultural Competency Training for Public Health Students: Integrating Self, Social, and Global Awareness Into a Master of Public Health Curriculum. Am J Public Health.[Internet] 2015;105(1) [acesso em 26 set 2015]. Disponível: http://dx.doi. org/10.2105/AJPH.2014.302506.

14. Praun AG. Sexualidade, gênero e suas relações de poder. Revista Húmus. [Internet] 2011;1(1) [acesso em 02 set 2015]. Disponível: http://www.periodicoseletronicos.ufma.br/index.php/revistahumus/article/view/1641/1302.

15. Marx J, Donaldson N. Constructing sexualities: A critical overview of articles published in Feminism \& Psychology. Feminism Psychology. [Internet] 2015;25(2) [acesso em 22 ago 2015]. Disponível: http://dx.doi. 
org/10.1177/0959353515572704.

16. Sung SC, Lin YC. Effectiveness of the sexual healthcare education in nursing students' knowledge, attitude, and self-efficacy on sexual healthcare. Nurse Educ Today. [Internet] 2013;33(5) [acesso em 22 ago 2015]. Disponível: http://dx.doi.org/10.1016/j.nedt.2012.06.019. 